\title{
Observing the Problems and Exploring the Solutions in the Process of English as a Second Language Teaching \& Learning
}

\author{
Dr. Pragya Mishra \\ Assistant Professor \\ Poornima University, Jaipur, Rajasthan, India
}

\begin{abstract}
"If I had an hour to solve a problem I'd spend 55 minutes thinking about the problem and 5 minutes thinking about solutions," says the great Scientist Albert Einstein. Everybody has their own understanding and perspectives towards teaching and learning English Language. In this new techno savvy era, there are number of educational options available for the ESL learners. The newer trends have shown a revolutionary change and brought an optimistic whirlpool in the traditional system of education. But whatever the teaching methodology is, learners and trainers are still facing problems in some or the other ways. This paper observes the obstacles hindering the process of English Language Teaching as well as English Language Learning and tries to explore effective solutions in order to reach to a positive and valuable conclusion.
\end{abstract}

Keyword: perspectives, whirlpool, obstacles, savvy etc.

\section{INTRODUCTION}

English Language has become the lingua franca of the world communiqué. People all over the globe are studying and learning English because it has become the language of education and business. Although we have a number of English medium schools, institutes for Spoken English and Soft Skills development in India but still learning level of the learners is not satisfactory and requires a serious restoration, enhancement and perfection so that educational and industrial needs can be fulfilled.

One can easily sense the impact of English today because of it's being in high demand. The teaching and learning of English is characterized by assortment of educational institutions encouraging linguistic environment for English acquisition but on the other hand encompassing classroom measures of teaching the topics for success in examination. Hence, English language teaching and learning can be broadly characterized within two aspects i.e. the teacher's English Language Proficiency and exposure of students to English for language acquisition. But as far as teaching English by the Teachers and learning it in order to enhance the communication skills are concerned, barriers are still being faced and desirability of new methodologies is augmenting day by day.

\section{Approach of Teachers towards English Language} Teaching

Earlier, students were taught English from fifth or sixth standard and moreover it was just like other subjects namely Physics, Chemistry etc. and as a result, students could hardly get exposure to use this language practically and enhance their speaking skills. The conventional methodologies used by the language teachers are:

Bilingual Method: Teachers follow this method in which the concept is taught in first language and then students are instructed to perform the activities in second language. Though this can prove beneficial in understanding the second language i.e. English but it doesn't help in the expression of language fluently and naturally.

Grammar Translation Method: Used by the teacher who explain everything in native language and then students translate the sentences in English by keeping the native language into mind leading to a disadvantage that students focus more on the native language rather than English language. 
$>$ Direct Method: This method has been into practice in most of the private institutes where a strict environment is made for the students to talk only in English and to some extent it has got success too. But still the natural attitude of speaking English is found missing somewhere.

The students are learning English as a subject rather than as a language and moreover a favorable and suitable aura for learning as well as understanding the language is not being created for them at all. Robert Bellarmine says that "the most serious problem in the teaching of English is the appalling small quantity and atrociously poor quality of English to which our learners are exposed."

\section{Problems faced by the Teacher in ELT:}

> Rigid mentality of the Students: College students who come from Hindi medium schools start developing inferiority complex that in any condition they won't be able to speak English. Peer Pressure adds fuel to the fire as the fear of becoming a laughing stock for other because of speaking incorrect English drags the students back and stops them to take initiative to come forward and perform. Moreover, the prevalent misunderstanding amongst the students that English is the most complicated subject sharpens their prejudiced vision and results in poor performance.

$>$ Learning process: As teacher tries to focus on all the basic skills of English Communication i.e. Listening, Speaking, Reading and Writing but students only concentrate on passing marks. At last, this lack of interest leads both the teacher and the students to take English learning as inescapable hurdle and anyhow they have to come out of it.

> Unavailability of Proper Audio-Visual Aids: Teachers find it difficult to teach English effectively because the aids provided for practice are not sufficient. Some are so costly that the colleges can only afford to buy few and as a result every student doesn't get the chance to use such tools for language learning and practicing.

$>$ Absence of Creativity in the Students: Students lack in self expression and feel lethargic in finding any possibility of creativity when it comes to essay writing, letter writing, grammar etc. they rely on notes provided by the teachers or readymade notes available at book shops. Their critical thinking and analytical skills remain dormant as to throw light on this issue Tej Bahadur Sapru has said,

What is known as a critical study of any author really means nothing more than picking up a few telling sentences or striking phrases from some book of criticism without real attempt at entering into the spirit of the author or appreciating his point of view. (17)

\section{Problems faced by the Students in English Language Learning:}

According to researchers, the English language learning heavily relies upon proper educational setting, which requires reasonable arrangements of several variables - experience and knowledge of teachers, students' needs and attitudes, and classroom. In other words, the classroom in ELT is considered as a social context for English language to perform and the teacher and students are key players. When students are asked whether they want to strengthen their Communication skills or not in spite of the fact that their medium of learning had been Hindi and they find it bit difficult to understand English spoken in British and American accent, the crux of their various opinions has come out as English Language in every aspect, Listening, Speaking, Reading and Writing is important because it increases the precision, accuracy aids in proper organization of thoughts. It provides a platform to express oneself creatively, provided one has sound knowledge of the vocabulary and can incorporate that knowledge along with impressive quotes and various literature theories.

Moreover, when observed from students' point of views, it is found that there are certain but very common issues causing serious barriers in the smooth functioning of English language learning process. The monitored barriers are:

$>$ Crowded Classrooms: The strength of the students remains about 50-60 per batch and so it becomes quite difficult to give attention to each and every student. Although there is a provision of Tutorial Class but unfortunately such classes are allotted to the subjects carrying more credits than English and of course, in any Engineering College, the weight age of English subject is very less and so it gets very less time i.e. 2 hours per week.

- Unsatisfactory Monitoring: The teachers in most of the colleges find it easier to guide smart students who are already good in English and thus 
fail to supervise those students who really need attention. As a result, such students develop disinterest towards English learning and the reluctance of the students also results in the discontinuation of effective activities as they lose confidence of speaking fluent English. A teacher is always expected to help weak students and guide them positively.

> Lack of Motivation: Teachers give tasks but they aren't interesting enough to motivate the students. Apart from this, consistent encouragement from the Teacher is very important as because of this only students will feel enlightened and won't hesitate to perform.

$>$ Lack of Exposure: Students spend more time in memorizing grammar rules, translating to and from one's native language and cramming vocabulary list without using them into a proper sentence structure and in real life situations.

$>$ Teachers suggest books according to their own choices but prove boring to the students.

$>$ The time schedule of the classes is also not frequent. For proper and rigorous training, language learning should be on regular basis.

Hence, as a result, students can strengthen only Writing and Reading Skills in comparison to Speaking and Listening.

\section{Exploring the Solutions:}

As it has already been mentioned that in the process of English Language learning, the role of / both Teacher and Students is important and so it becomes vital point to be taken under consideration that both of them will have to understand their roles for making this effort of achieving success in Language learning, a productive one. The ESL trainer or a teacher must know how:

\section{$>$ To facilitate an interactive communicative} opportunities and establish situations that induce students to communicate in English: The crucial role of the teacher is to keep the communication going between all members of the class as they perform various activities. The teacher will have to prepare the activities taking care of Students' interest and then explain how they will be carried out. It may be necessary for the teacher to provide examples of how each activity will be performed. Once the activity is under way, the teacher will check on individual groups to see if they are communicating effectively and gives help where needed.
To participate and guide: As an alternative, the teacher may take the role of an active participant in each learning group and guide the students what exactly they are supposed to do.

To be the Need Analyst: As a need analyst, the teacher is expected to determine and respond to students' language needs. This engages motivating the students to participate into the designed activities and making them aware about what they are doing right and wrong. Though pointing out mistakes in the process of activity won't be good for the students as they may lose confidence and feel hesitant to perform again but teacher can make notes on errors made by the students and plan future activities to rectify these errors and replenish students' needs.

To focus on the function: The teacher is expected give emphasis on the function rather than form of the language and keeps monitoring the performance and provides feedback.

Methodologies that can be used in English Language Teaching:

Modelling which is basically like confronting anyone with a problem, striking up conversation in a class, or being assertive. Afterward, just debrief with the students as to what you did and why.

Write Rehearse and Speak (WRS) is an activity that can be very beneficial for the students who feel reluctant in speaking English at an open platform. Teacher will provide students with various topics based on current affairs and ask them to write an article on any one topic of their choice. After making corrections (if required) in their articles, they will be motivated to read their article in front of others and they may use the paper while doing so. Then the third stage would be speaking on the same article without looking at the paper. This is one of the most beneficial activities that help in enhancing the confidence of the students to speak English.

$>$ Role Play: One of the best methods of preparing teens for real life is to rehearse situations. Role playing offers them the chance to practice how to act in a situation that is non-threatening. Teacher can come up with innovative situations based on current scenarios let the students develop their scripts and play the parts. At the beginning, the students may start the role play by learning the dialogues by heart and later on substitute variables in the same core structure. 
Audio-Lingual Activities: Using Audio-visual tools add on creating an apt environment for English Language learning. Nowadays, every student carries MP3 player or mobile phones and so teacher may provide students with important English learning audios so that they can practice them at home too. Students listen to native speakers and then try to imitate them. Though in order to acquire exact native English accent, one has to go through rigorous training and practice but just listening to English help the students to understand the proper structure of English Sentence and grammatical usage.

$>$ Watch \& Speak: Teacher can use flash cards showing any particular scene, person and familiar word one by one and after a series of things, students will have to speak something on those pictures. This activity is very effective for developing students' creativity and prompt speaking skills.

$>$ Vocabulary Games: Vocabulary knowledge is one of the main components of Communication skills. It enables language use and vice versa. Although one may ask "how many words are needed to do make your English communication strong?" so, Language teacher may come up with frequently used English words everyday and ask students to practice them whole day in their speech even if they talking in their native language. Apart from this, reading books play a significant role in enriching vocabulary knowledge of the students. Under positive conditions, a vocabulary size can be as follows depending on the words coverage in novels or other books for teens:

$>$

\begin{tabular}{|c|c|c|}
\hline $\begin{array}{c}\text { Vocabulary } \\
\text { Size }\end{array}$ & $\begin{array}{c}\% \\
\text { Coverage }\end{array}$ & $\begin{array}{c}\text { Density of } \\
\text { Unknown Words }\end{array}$ \\
\hline 1000 words & $90 \%$ & 2 in every 10 \\
\hline $\begin{array}{c}2500+ \\
\text { Proper Noun }\end{array}$ & $94 \%$ & 2 in every 18 \\
\hline 3000 words & $96 \%$ & 2 in every 27 \\
\hline 5500 words & $98 \%$ & 2 in every 70 \\
\hline
\end{tabular}

Students come across plethora of vocabulary everyday but using them appropriately is the main point for concern and for that effective vocabulary instruction should be given by the teacher which are
- Definitional and contextual information about the word.

- Numerous uses of the word in different framework.

- Persuading students to participate with enthusiasm.

\section{Using different methods like Communicative} Language Teaching, Learning by Teaching etc. Such methods ignite Cooperative and Collaborative learning that basically emphasizes on students' team spirit, encouraging inherent motivation and enhancing self admiration etc. The interactive learning has always supported interactive communications and thus creates more and more opportunities for the students to work in groups and make English language speaking a natural process.

$>$ Provide feedback: The most important methodology is to always provide feedback. Observe the student in different situations and then share with him/her whatever you observed. This will help them to know areas where they require improvement. Both negative and positive feedbacks are essential and also offer suggestions, if necessary.

Hence, English Language teaching can come out to be a fruitful effort when the students appear to possess the attributes like

$>$ The desire to listen to the English Language

$>$ The willingness to experiment with the language.

$>$ Taking the initiative to ask questions.

$>$ Develop acumen to innovate different learning process.

$>$ Positive acceptance of error identification and correction.

Most important, nourishing the desire To Learn.

To conclude, it can be said that Teaching or learning English as a second Language is ecstatic and enlightening experience if it is done less seriously --But More Sincerely. English language has taken a place of prestige and grandeur in our country and it is undeniable fact that generation will keep coming and going but the colossal stature of this language will always remain the same. So we have to consider the standard of teaching level that is, unfortunately, deteriorating and try to find out possible ways to get rid of all the barriers for effective and better results. 


\section{References}

1. A. Suad Ahmed, A. Lamees, "Investigating students attitudes and preferences towards learning English at Kuwait University"; College Student Journal. 2009.

2. Barret, S. (2002).Overcoming Transactional Distance as a Barrier to Effective Communication over the Internet. International Education Journal, 3(4), Educational Research Conference 2002, Special Issue.

3. Best, J. W., \& Khan, J. W. (2012). Research in Education (10thed.). New Delhi: PHI Learning Private Ltd.

4. Collins, J. (1997). Barriers to Communication in Schools. (Presentation paper). British Educational research Association Annual Conference, University of York.
5. L. Ducate, and L. Lomicka, "Podcasting: An effective tool for honing language students' pronunciation," Language learning \&technology; 2009.

6. M. Cluck, D. Hess, Improving student motivation through the use of the multiple intelligences, 2003.

7. M. East, "Promoting positive attitudes towards foreign language learning: A New Zealand initiative"; Journal of multilingual and multicultural development; 2009.

8. S. Sharada, A study of the predictors of academic success among high school English language learners in one urban Tennessee School District, Ed. D, Tennessee State University, 2009. 